\title{
Case report: Endotracheal tube malposition in a patient with a tracheal bronchus
}

\author{
[Présentation de cas: malposition du tube endotrachéal chez une patiente qui pré-
} sente une bronche trachéale]

David T. Wong MD, Ashok Kumar B DA

Purpose: A tracheal bronchus is a congenital abnormality of the tracheobronchial tree, in which a displaced or accessory bronchus arises from the trachea superior to its bifurcation. We report a patient with a tracheal bronchus that was found incidentally during surgery in the prone position, and the potential airway management problems which may have ensued.

Clinical features: A 70-yr-old female underwent posterior spinal decompression and fusion in the prone position. Intraoperatively, end-tidal $\mathrm{CO}_{2}$ and airway pressure increased. Fibreoptic bronchoscopy revealed that the endotracheal tube (ETT) was kinked at the $16 \mathrm{~cm}$ mark, which was corrected by rotating the patient's head and ETT. When the bronchoscope was advanced beyond the tip of the ETT, a tracheal-bronchial tree trifurcation was identified. Endobronchial intubation was suspected. As the ETT was withdrawn, the endoluminal view remained unchanged. During bronchoscopy, the patient's trachea was nearly extubated in the prone position. Subsequent bronchoscopy of the major bronchial divisions showed that the trifurcation represented left main stem bronchus, bronchus intermedius and right upper lobe bronchus. Once the tracheal bronchus was recognized, the tip of the ETT was repositioned $3 \mathrm{~cm}$ above the tracheal trifurcation, and the rest of the case was uneventful.

Conclusion: This case highlights the diagnostic challenge and airway management implications of one variant of a tracheal bronchus when airway problems are encountered intraoperatively. This knowledge should be applied in the differential diagnosis and management of intraoperative hypoxemia; and in the proper positioning of the ETT.
Objectif : La bronche trachéale est une anomalie congénitale de l'arbre trachéobronchique où une bronche aberrante ou accessoire s'insère à la trachée au-dessus de sa bifurcation. Nous présentons un cas de bronche trachéale découverte accidentellement pendant une opération en décubitus ventral, et les problèmes potentiels de la prise en charge des voies aériennes qui auraient pu s'ensuivre.

Éléments cliniques: Une femme de 70 ans a subi une décompression et une fusion vertébrales postérieures en décubitus ventral. Pendant l'opération, le $\mathrm{CO}_{2}$ télé-expiratoire et la pression des voies aériennes se sont élevés. La fibroscopie bronchique a révélé un coude dans le tube endotrachéal (TET) à $16 \mathrm{~cm}$, ce qui $a$ été corrigé par une rotation de la tête de la patiente et du TET. Quand le bronchoscope a été poussé au delà de la pointe du TET, une trifurcation de l'arbre trachéobronchique a été dépistée et une intubation endobronchique présumée. Au retrait du TET, la visualisation endoluminale est demeurée inchangée. Pendant la bronchoscopie, la trachée de la patiente était presque extubée en décubitus ventral. Une bronchoscopie subséquente des divisions bronchiques principales a montré une bronche souche gauche, une bronche intermédiaire et une bronche du lobe supérieur droit. Une fois identifiée la bronche trachéale, la pointe du TET a été replacée $3 \mathrm{~cm}$ au-dessus de la trifurcation trachéale et l'opération s'est poursuivie normalement.

Conclusion : Ce cas illustre le défi du diagnostic, et les implications sur la prise en charge des voies aériennes, d'une variante d'une bronche trachéale révélée par des problèmes d'intubation peropératoires. Ce savoir devrait être appliqué au diagnostic différentiel et au traitement de l'hypoxémie peropératoire, ainsi qu'à la mise en place correcte du TET.

From the Department of Anesthesiology, Toronto Western Hospital, University Health Network, University of Toronto, Toronto, Ontario, Canada.

Address correspondence to: Dr. David T. Wong, Department of Anesthesiology, MC 2-405, Toronto Western Hospital, 399 Bathurst

Street, Toronto, Ontario M5T 2S8, Canada. Phone: 416-603-5118; Fax: 416-603-6494; E-mail: david.wong@uhn.on.ca

This work was supported in part by the Department of Anesthesiology, Toronto Western Hospital, University of Toronto.

Accepted for publication February 16, 2006.

Revision accepted February 23, 2006.

Competing interests: None declared. 


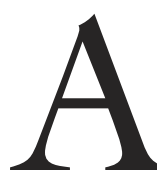

tracheal bronchus is a congenital abnormality of the tracheobronchial tree, in which a displaced or accessory bronchus arises from the trachea superior to its bifurcation at the carina. The main clinical implication of a tracheal bronchus arises during endotracheal intubation. ${ }^{1}$ An endotracheal tube (ETT) can obstruct or migrate into a tracheal bronchus causing pulmonary atelectasis, hypoxia or both. ${ }^{2-4}$ We report a patient with a tracheal bronchus that was found incidentally during surgery, and the potential mismanagement it could have caused.

\section{Case report}

The case was submitted to the institutional Research Ethics Board for review. As the patient had deceased at the time of writing this report, no informed consent from the patient's family was deemed necessary.

The patient was a 70 -yr-old $59 \mathrm{~kg}, 152 \mathrm{~cm}$ female, with a three-month history of left sided chest wall neuropathic pain. She presented to the emergency room with a one-day history of leg weakness and urinary incontinence. A magnetic resonance imaging scan of her spine showed spinal cord compression from T6-T11. She was scheduled for emergency posterior spinal decompression and fusion in the prone position. Routine anesthetic monitors were applied, and anesthesia was induced with fentanyl, propofol and rocuronium. The patient's trachea was intubated orally using a 7.5-mm ETT. After ausculatatory confirmation of bilateral breath sounds, the ETT was secured with the $20-\mathrm{cm}$ mark at the patient's upper incisors. The patient's lungs were mechanically ventilated to achieve eucapnia and anesthesia was maintained with nitrous oxide/oxygen and desflurane. The patient was turned to the prone position on a Wilson frame and her head was positioned on a head rest (Gentle Touch ${ }^{\circledR}$ head rest pillow, Orthopedic system Inc., Union City, CA, USA).

After two and a half hours the end-tidal $\mathrm{CO}_{2}$ $\left(\mathrm{ETCO}_{2}\right)$ increased gradually from 37 to $62 \mathrm{mmHg}$, despite adjustments to increase minute ventilation. The airway pressure increased from 28 to $33 \mathrm{~cm} \mathrm{H}_{2} \mathrm{O}$. An arterial blood gas analysis showed $\mathrm{pH}=7.11$, $\mathrm{pCO}_{2}=65 \mathrm{mmHg}$ and $\mathrm{pO}_{2}=171 \mathrm{mmHg}$. There was no evidence of obstruction in the anesthesia circuit or valves. On auscultation of the chest, breath sounds were decreased bilaterally. The $\mathrm{SpO}_{2}$ remained $\geq 98 \%$.

Fibreoptic bronchoscopic examination identified that the ETT was kinked at the $16 \mathrm{~cm}$ mark. The kink was relieved by rotating the patient's head $30^{\circ}$ to the right, and rotating the ETT. Airway pressure

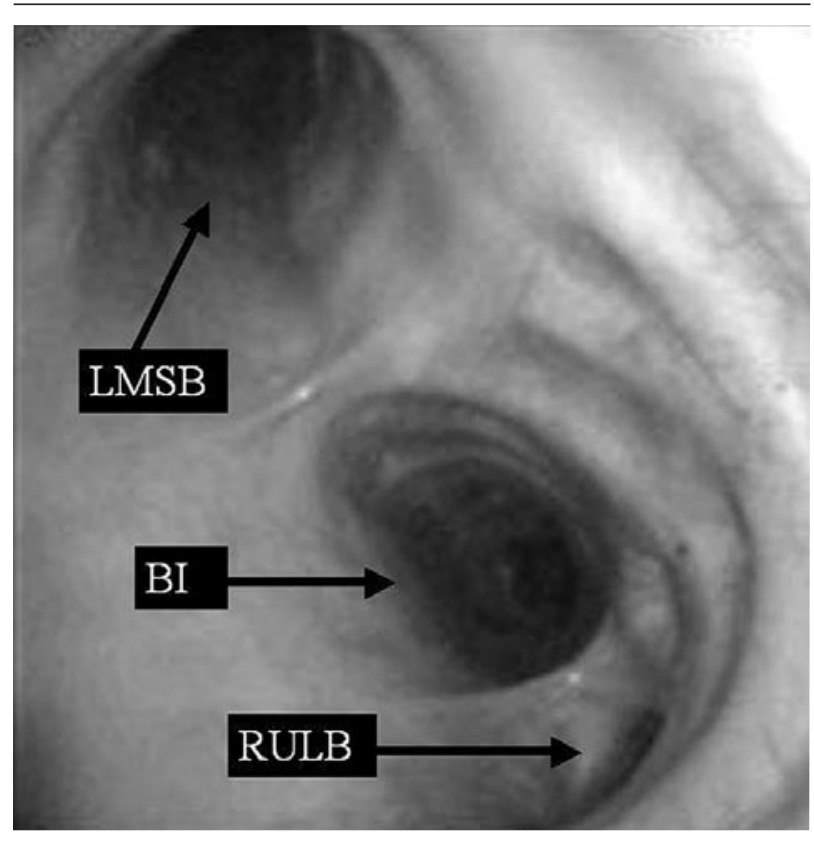

FIGURE 1 Bronchoscopic view of the trachea at the level of carina showed a trifurcation. The three divisions represented are the left main stem bronchus (LMSB), bronchus intermedius (BI) and right upper lobe bronchus (RULB).

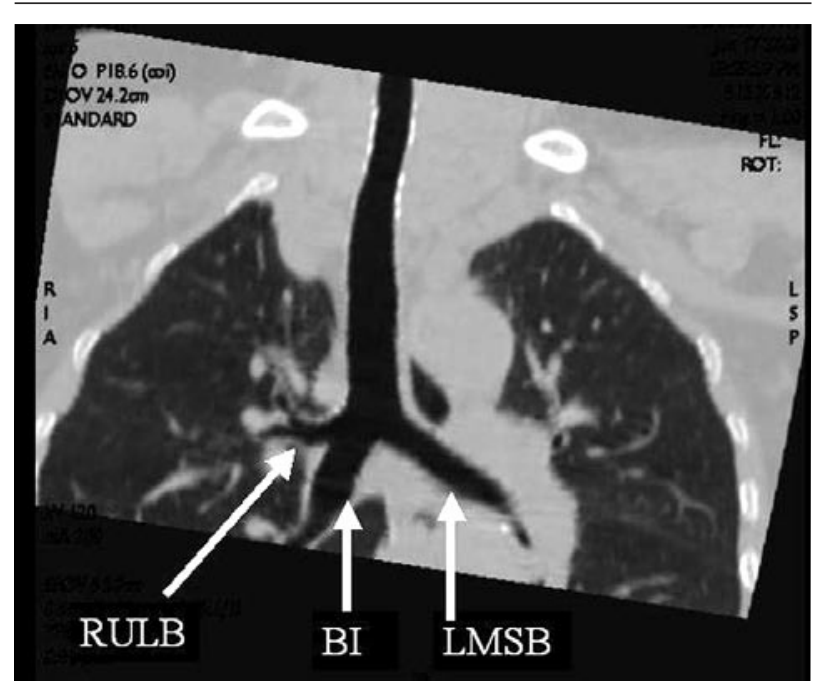

FIGURE 2 A three-dimensional coronal reconstructed view of the tracheobronchial tree from the thoracic computed tomography showing trifurcation of the trachea labelled as: right upper lobe bronchus (RULB), bronchus intermedius (BI) and left main stem bronchus (LMSB). 


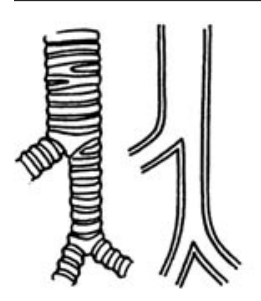

[I]

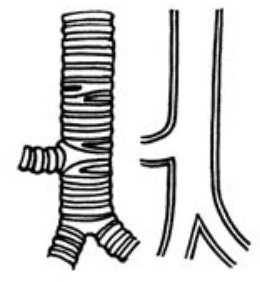

[II]

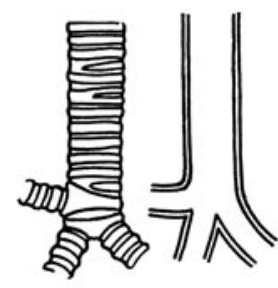

[III]
FIGURE 3 Schematic representation of the three types of tracheal bronchus likely to be of significance to anesthesiologists. They represent displaced right upper lobe tracheal bronchus (I), supernumerary right upper lobe tracheal bronchus (II) and displaced right upper lobe tracheal bronchus as tracheal trifurcation (III). Reprinted from Conacher, ${ }^{8}$ with permission from Oxford University Press.

and $\mathrm{ETCO}_{2}$ decreased from 33 to $28 \mathrm{~cm} \mathrm{H}_{2} \mathrm{O}$ and 62 to $45 \mathrm{mmHg}$ respectively, over ten minutes. When the bronchoscope was advanced beyond the tip of the ETT, a tracheal-bronchial tree trifurcation was seen (Figure 1). This finding led to the suspicion of endobronchial intubation. As the ETT was withdrawn from $20 \mathrm{~cm}$ to $16 \mathrm{~cm}$, the endoluminal view remained unchanged. In this process, the patient's ETT was nearly removed from the trachea. Subsequent bronchoscopy of the major bronchial divisions showed that the trifurcation represented left main stem bronchus, bronchus intermedius and right upper lobe bronchus (Figure 1). The tip of the ETT was positioned $3 \mathrm{~cm}$ above the carina and the ETT was fixed at the $19 \mathrm{~cm}$ mark relative to the upper incisors. Bilateral breath sounds were confirmed. The $\mathrm{ETCO}_{2}$ and airway pressure normalized. The surgery was uneventful thereafter, and postoperatively the patient was transferred to the intensive care unit. Her trachea was extubated without incident $12 \mathrm{hr}$ later.

Tissue pathology from the surgical specimen indicated Burkitt's lymphoma. A three-dimensional coronal reconstructed view of the tracheobronchial tree from the thoracic computed tomography showed trifurcation of trachea (Figure 2). The patient died five months later from complications related to her cancer.

\section{Discussion}

Tracheal bronchus was first described by Sandifort in $1785 .^{5}$ This anomaly involves a displaced or supernumerary (accessory) bronchus arising from the lateral wall of the trachea. ${ }^{6}$ The tracheal bronchus is most commonly seen as a displaced apical segmental bron- chus, but it may be a supernumerary apical segmental bronchus, a displaced upper lobe bronchus or more rarely, a supernumerary upper lobe bronchus. ${ }^{7}$ It can arise anywhere between the carina and cricoid cartilage, but is most frequently seen within $2 \mathrm{~cm}$ of the carina, ${ }^{6,8}$ and has been reported as high as $6 \mathrm{~cm}$ above the carina. ${ }^{1,8-10}$ It is much more common on the right side than the left. ${ }^{6,7}$ The incidence of tracheal bronchus is reported to be approximately $0.5-3.0 \%{ }^{7,11,12}$ Several variants of tracheal bronchus are depicted in Figure $3 .^{8} \mathrm{~A}$ tracheal bronchus involving the upper lobe bronchus has more important anesthetic implications than involvement of the segmental bronchus, as obstruction by an ETT or double-lumen tube would result in a larger area of atelectasis and shunting. ${ }^{6,8,11}$ A tracheal bronchus also may occur in association with other congenital anomalies such as tracheoesophageal fistula, tracheal stenosis and Down's syndrome. ${ }^{10-15}$ Recognition of a tracheal bronchus before induction of anesthesia can be helpful for determining optimal positioning of the ETT. ${ }^{1}$ More frequently, the anesthesiologist may be unaware of the presence of tracheal bronchus, which could have important implications in the diagnosis and management of intraoperative hypoxia or atelectasis.

Endotracheal intubation in a patient with a tracheal bronchus can cause obstruction of the tracheal bronchus leading to shunting and hypoxemia. Intubation of the tracheal bronchus may result in hypoxia, atelectasis, or both during anesthesia. In this case, even though hypercapnia was not caused by the presence of a tracheal bronchus and hypoxemia was not encountered, the potential for a serious adverse event existed. If the tracheal anatomic anomaly had not been diagnosed immediately once airway problems were identified, the ETT could have been withdrawn completely, with the patient in prone position. If the patient's trachea had been extubated, reinsertion of the ETT over the fibreoptic bronchoscope would have been very challenging due to prone positioning, lack of physical space for locating airway equipment, secretions, airway edema, and potential catching of the ETT leading edge at the level of the vocal cord or arytenoid cartilage. ${ }^{16}$

In this patient, an increase in end-tidal $\mathrm{CO}_{2}$ and the rise in airway pressure were caused by kinking of the ETT inside the oropharyngeal cavity. The reason for kinking of the ETT could be attributed to the prone position of the patient, flexion of the head, and softening and compression of the ETT in a warm oropharyngeal space. Airway obstruction was relieved by head and ETT rotation. If the airway obstruction had remained unresolved with the above- 
mentioned maneuvers, the patient would have to be turned supine to re-intubate her trachea. The use of an armored or reinforced ETT may have prevented kinking of the ETT.

In summary, our case illustrated two interesting management issues. The first issue consisted of gradual increases in end-tidal $\mathrm{CO}_{2}$ values and airway pressures secondary to a kinked ETT within the oropharynx. This problem was relieved by head and ETT rotation. Secondly, bronchoscopy beyond the ETT tip disclosed trifurcation of the tracheal-bronchial tree. Initial failure to recognize the presence of a tracheal bronchus led to withdrawal of the ETT, nearly resulting in unintended tracheal extubation with the patient in prone position. Once the diagnosis had been confirmed, the ETT was properly positioned within the trachea. Anesthesiologists should be familiar with the anatomy and anesthetic implications of a tracheal bronchus. This knowledge should be applied in the differential diagnosis and management of intraoperative hypoxemia, and in bronchoscopic confirmation of ETT positioning when airway management problems arise.

\section{Acknowledgement}

We sincerely thank Dr. Glenn McGuire for his helpful comments in the preparation of this manuscript.

\section{References}

1 Ikeno S, Mitsubata H, Saito K, et al. Airway management for patients with a tracheal bronchus. Br J Anaesth 1996; 76: 573-5.

2 O'Sullivan BP, Frassica JJ, Rayder SM. Tracheal bronchus: a cause of prolonged atelectasis in intubated children. Chest 1998; 113: 537-40.

3 Pribble CG, Dean JM. An unusual cause of intraoperative hypoxemia. J Clin Anesth 1994; 6: 247-9.

4 Vredevoe LA, Brechner T, Moy TP. Obstruction of anomalous tracheal bronchus with endotracheal intubation. Anesthesiology 1981; 55: 581-3.

5 Kubik S, Muntener M. Bronchus abnormalities: tracheal, eparterial and pre-epartrial bronchi (German). Fortschr Geb Rontgenstr Nuklearmed 1971; 114: 145-63.

6 Ghaye B, Szapiro D, Franchamps JM, Dondelinger $R F$. Congenital bronchial abnormalities revisited. Radiographics 2001; 21: 105-19.

7 Hansell DM. The normal chest. In: Hansell DM, Armstrong P, Lynch DA, McAdams HP (Eds). Imaging of the Diseases of the Chest, $4^{\text {th }} \mathrm{ed}$. Philadelphia: Elsevier Ltd.; 2005: 29.

8 Conacher ID. Implication of a tracheal bronchus for adult anaesthetic practice. Br J Anaesth 2000; 85:
317-21.

9 Gerson CE, Rothstein E.An anomalous tracheal bronchus to the right upper lobe. Am Rev Tuberc 1951; 64: 686-90.

10 Siegel MJ, Shackelford GD, Francis RS, McAlister MW. Tracheal bronchus. Radiology 1979; 130: 353-5.

11 Doolittle AM, Mair EA. Tracheal bronchus: classification, endoscopic analysis, and airway management. Otolaryngol Head Neck Surg 2002; 126: 240-3.

12 McLaughlin FJ, Strieder DJ, Harris GB, Vawter GP, Eraklis AJ. Tracheal bronchus: association with respiratory morbidity in childhood. J Pediatr 1985; 106 : 751-5.

13 Cantrell JR, Guild HG. Congenital stenosis of the trachea. Am J Surg 1964; 108: 297-305.

14 Laforet EG, Starkey GW, Scheff S. Anomalies of upper lobe bronchial distributions. J Thorac Cardiovasc Surg 1962; 43: 595-606.

15 Le Roux BT. Anatomical abnormalities of the right upper lobe bronchus. J Thorac Cardiovasc Surg 1962; 44: 225-7.

16 Johnson DM, From AM, Smith RB, From RP, Maktabi $M A$. Endoscopic study of mechanisms of failure of endotracheal tube advancement into the trachea during awake fiberoptic orotracheal intubation. Anesthesiology 2005; 102: 910-4. 